\title{
In-situ multispectral and bathymetric measurements over a supraglacial lake in western Greenland using a remotely controlled watercraft
}

\author{
M. Tedesco ${ }^{1,2}$ and N. Steiner ${ }^{1,2}$ \\ ${ }^{1}$ The City College of New York, CUNY, NYC, NY, USA \\ ${ }^{2}$ The Graduate Center, CUNY, NYC, NY, USA
}

Received: 31 December 2010 - Published in The Cryosphere Discuss.: 7 February 2011

Revised: 17 May 2011 - Accepted: 20 May 2011 - Published: 27 May 2011

\begin{abstract}
Supraglacial lakes form from meltwater on the Greenland ice sheet in topographic depressions on the surface, affecting both surface and sub-glacial processes. As the reflectance in the visible and near-infrared regions of a column of water is modulated by its height, retrieval techniques using spaceborne remote sensing data (e.g. Landsat, MODIS) have been proposed in the literature for the detection of lakes and estimation of their volume. These techniques require basic assumptions on the spectral properties of the water as well as the bottom of the lake, among other things. In this study, we report results obtained from the analysis of concurrent in-situ multi-spectral and depth measurements collected over a supraglacial lake during early July 2010 in West Greenland (Lake Olivia, 69 $36^{\prime} 35^{\prime \prime} \mathrm{N}$, $49^{\circ} 29^{\prime} 40^{\prime \prime} \mathrm{W}$ ) and aim to assess some of the underlying hypotheses in remote sensing based bathymetric approaches. In particular, we focus our attention on the analysis of the lake bottom albedo and of the water attenuation coefficient. The analysis of in-situ data (collected by means of a remotely controlled boat equipped with a GPS, a sonar and a spectrometer) highlights the exponential trend of the water-leaving reflectance with lake depth. The values of the attenuation factor obtained from in-situ data are compared with those computed using approaches proposed in the literature. Also, the values of the lake bottom albedo from in-situ measurements are compared with those obtained from the analysis of reflectance of shallow waters. Finally, we quantify the error between in-situ measured and satellite-estimated lake depth values for the lake under study.
\end{abstract}

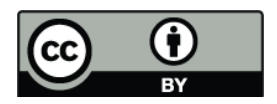

Correspondence to: $\mathrm{M}$. Tedesco (mtedesco@sci.ccny.cuny.edu)

\section{Background and rationale}

Supraglacial lakes are pools of meltwater that form during summer in depressions in the ice sheet surface. Monitoring the spatio-temporal variability of such lakes over the Greenland ice sheet (GrIS) can benefit studies concerning ice sheet dynamics (Das et al., 2008; Joughin et al., 1996; Pimentel and Flowers, 2010) and surface features (e.g., Lüthje et al., 2006) and can help understanding their link with recently observed increased surface melting (Tedesco et al., 2011). Recently, several approaches based on the interpretation of visible and near-infrared satellite data have been proposed for estimating supraglacial lake depth (e.g., Georgiou et al. 2009; Box and Ski, 2007). McMillan et al. (2007) use satellite imagery to study the evolution of 292 lakes over an area of $22000 \mathrm{~km}^{2}$; Sundal et al. (2009) analyze 268 cloud-free Moderate Resolution Imaging Spectroradiometer (MODIS) images; Sneed and Hamilton (2007) estimate the depth of selected lakes based on Advanced Spaceborne Thermal Emission and Reflection radiometer (ASTER) atmospherically corrected reflectance values.

The reflectance of a water column limited by a reflecting bottom can be approximated with the reflectance of the same water body in absence of a bottom plus the bottom contrast, after this contrast has been modulated by the depth of the bottom through an attenuation factor (Philpot, 1989; Maritorena, 1994). Box and Ski (2007) use MODIS atmospherically corrected reflectance values to compute lake area and volume for those pixels where the presence of a lake is detected. In their study, a pixel is classified as lake if the MODIS band $1(620-670 \mathrm{~nm})$ reflectance is below 0.6 and the ratio $\mathrm{R}_{b 3 / b 1}=$ band3/band1 is greater than 1.25 (with band 3 being $459-479 \mathrm{~nm}$ ). Moreover, those pixels with reflectance values of the band 6 greater than 0.15 are excluded from

Published by Copernicus Publications on behalf of the European Geosciences Union. 
the analysis to reduce the impact of cloud cover (Box and Ski, 2007). For those pixels where a lake is detected, lake depth is then estimated using a regression formula obtained from the fitting of in-situ lake depth measurements to satellite reflectance values. The main advantage of the method proposed by Box and Ski (2007) lies in its low computational cost. However, results are based on a limited number of measurements over selected lakes and the extension of the method to other areas would require further validation and assesment. A physically-based retrieval has been proposed by Sneed and Hamilton (2007). This is the approach that will be used in this study as it offers the opportunity to evaluate some of the theoretical assumptions adopted in the retrieval scheme. The approach is briefly described and discussed in the following.

For retrieval purposes, the following hypotheses on the bottom albedo $A d$ and on the attenuation factor $g$ are made: (hyp. 1) in the absence of actual measurements the value of $A d$ is assumed to be uniform and (hyp. 2) Ad is estimated from reflectance values of shallow waters along the lake edge (e.g., Sneed and Hamilton, 2007); the attenuation factor $g$ is computed assuming that (hyp. 3) suspended or dissolved organic or inorganic particulate matter is minimal and that (hyp. 4) a linear relationship exists between the attenuation factor and the diffuse attenuation coefficient (e.g., Maritorena, 1994). Measurements of organic, chlorophyll and suspended minerals by Sneed and Hamilton (2007) confirmed that concentrations are appreciably small (less than $1 \mathrm{mg} \mathrm{L}^{-1}$ ). Similar concentrations were confirmed by our analysis of water samples collected from different lakes. Though spectrally similar to the diffuse attenuation coefficient for downwelling light $K d, g$ and $K d$ cannot be used interchangeably and a possible range of $1.5 \mathrm{Kd}<\mathrm{g}<3 \mathrm{Kd}$ is suggested by Philpot (1989) in the case of strongly absorbing waters. The value of $g \approx \alpha \cdot K d$ with $\alpha=2$ has been used by Sneed and Hamilton (2007) and Maritorena et al. (1994), with the latter warning that such a choice will lead to an unquantifiable underestimation of the actual attenuation.

Focusing on the bottom albedo $A d$, Sneed and Hamilton (2007) and Georgiou et al. (2009) suggest that the dominant uncertainty is in the the selection of $A d$. As said, for this parameter the assumption of a uniform distribution over the lake area is used for retrieval purposes and its value is estimated from the pixels adjacent to those showing a rapid decrease in the red band (Sneed and Hamilton, 2007). In other words, because of the relatively small attenuation in the green and blue bands with respect to the red band, the bottom albedo $A d$ is assumed to be spectrally similar to the pixels where water is shallow, at the edge of the lake.

The assumptions applied to the estimation of $A d$ and the choice of $\alpha$ are a source of uncertainty on the accuracy of lake depth retrieval from spaceborne data. Here we report, for the first time, in-situ concurrent spectral and depth data collected over a supraglacial lake in West Greenland by means of instruments mounted on a remotely controlled boat.
We analyze the spatial distribution of $A d$ to assess the hypothesis of its spatial uniformity and compare $A d$ mean values with those obtained from shallow waters at the lake edge. We also study the spectral dependency of both $A d$ and $g$ obtained from in-situ measurements and compare their values against those obtained using literature approaches. This analysis is extended to satellite methods for the estimates of lake depth from either the Landsat and MODIS sensors with those obtained in-situ, quantifying the uncertainty of current procedures for multispectral bathymetry of supraglacial lakes.

\section{Supraglacial lake bathymetry from visible data}

In the following, we briefly summarize the equations used for estimating lake depth from visible data, together with the hypotheses behind the retrieval scheme.

The expression for reflectance immediately below the water surface for optically shallow, homogeneous water is given by (Philpot, 1989):

$R\left(0^{-}\right)=R_{\infty}+\left(A d-R_{\infty}\right) \exp (-g z)$

where $A d$ is the irradiance reflectance (albedo) of the bottom, $A d=E u(z) / E d(z)$, with $E u$ being the upwelling irradiance and $E d$ the downwelling irradiance at depth $z$, and $R_{\infty}$ is the irradiance reflectance of an optically deep water column. Solving Eq. (1) for $z$ gives:

$z=-\left(\ln \left(A d-R_{\infty}\right)-\ln \left(R\left(0^{-}\right)-R_{\infty}\right) / g\right.$

The coefficient $g$ accounts for losses in both the upward and downward directions and is given by $g \approx K d+a D u$ (Philpot, 1989), where $K d$ is the diffuse attenuation coefficient for downwelling light, $a$ is the beam absorption coefficient, and $D u$ is an upwelling light distribution function or the reciprocal of the upwelling average cosine (Mobley, 2004). According to Philpot (1989), the two attenuation coefficients $g$ and $K d$ are spectrally similar as long as the diffuse attenuation is not dominated by scattering. However, $K d$ and $g$ cannot be used interchangeably and a possible range of 1.5 $K d<g<3 K d$ can be assumed in the case of strongly absorbing waters. Philpot (1989) approximates $g \approx 2 K d$, for purposes of computation (Table 1, Philpot 1989). In this study, we use the values of the diffuse attenuation coefficient $K d$ of optically pure water by Pope and Fry (1997).

\section{The remotely controlled boat and the instruments}

A commercially-available remotely controlled boat (http: //www.viperfishing.co.uk/Site/Viper_Storm_2.html, Fig. 1) was customized and equipped with a GPS/sonar (HDS-5 Lowrance), an above-surface irradiance sensor for incoming solar radiation, a below-surface downward looking radiance sensor, a spectrometer (Ocean Optics) and a micro computer (used to synchronize the data from the different instruments). The boat is made of glossy acrylic capped ABS 
Table 1. Statistics on lake depth retrieval using different space-borne sensors, bands and hypotheses on the value of the $\alpha$ coefficient.

\begin{tabular}{|c|c|c|c|c|c|}
\hline & Mean $[\mathrm{m}]$ & Std. dev. $[\mathrm{m}]$ & Max. $[\mathrm{m}]$ & $\operatorname{RMSE}[\mathrm{m}]$ & Correlation \\
\hline SONAR & 2.83 & 0.97 & 4.55 & $\mathrm{n} / \mathrm{a}$ & $\mathrm{n} / \mathrm{a}$ \\
\hline \multicolumn{6}{|c|}{ Landsat BAND $1(450-515 \mathrm{~nm})$} \\
\hline$\alpha=2$ & 5.95 & 1.47 & 8.21 & 2.76 & 0.78 \\
\hline$\alpha=1.91$ & 5.98 & 1.52 & 8.35 & 3.02 & 0.77 \\
\hline \multicolumn{6}{|c|}{ Landsat BAND 2 (525-605 nm) } \\
\hline$\alpha=2$ & 3.64 & 0.91 & 4.87 & 0.67 & 0.85 \\
\hline$\alpha=2.33$ & 2.92 & 0.78 & 4.21 & 0.59 & 0.87 \\
\hline \multicolumn{6}{|c|}{ MODIS TERRA (AQUA) - BAND 3 (459-479 nm) } \\
\hline$\alpha=2$ & $6.5(2.3)$ & $1.93(1.47)$ & $8.65(4.14)$ & $\mathrm{n} / \mathrm{a}$ & $\mathrm{n} / \mathrm{a}$ \\
\hline$\alpha=1.91$ & $6.93(2.44)$ & $2.04(1.56)$ & $9.18(4.39)$ & $\mathrm{n} / \mathrm{a}$ & $\mathrm{n} / \mathrm{a}$ \\
\hline \multicolumn{6}{|c|}{ MODIS TERRA (AQUA) - BAND 4 (545-565 nm) } \\
\hline$\alpha=2$ & $2.1(0.9)$ & $0.92(0.9)$ & $2.9(1.9)$ & $\mathrm{n} / \mathrm{a}$ & $\mathrm{n} / \mathrm{a}$ \\
\hline$\alpha=2.33$ & $1.71(0.71)$ & $0.75(0.74)$ & $2.44(1.56)$ & $\mathrm{n} / \mathrm{a}$ & $\mathrm{n} / \mathrm{a}$ \\
\hline
\end{tabular}

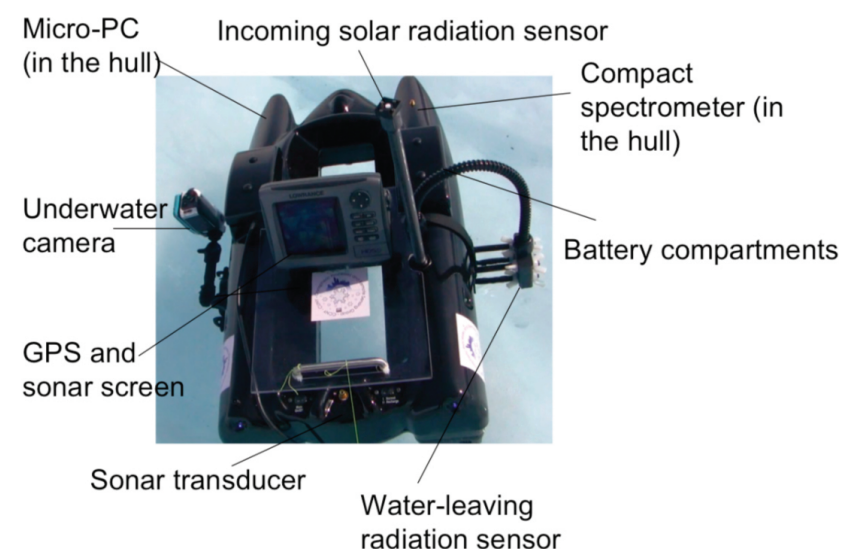

Fig. 1. The customized remotely controlled boat with the different instruments

and propelled by dual jet-pump engines. Lake depth was measured by means of a $50 / 200 \mathrm{kHz}$ transducer. The depth uncertainty was estimated to be of the order of $20-30 \mathrm{~cm}$ by testing the set up in a swimming pool before the shipping and deployment to Greenland. However, the uncertainty on depth might be higher than the one obtained in the pool because of the roughness of the bottom of the supraglacial lake, which might be responsible for multiple echos. The boat is designed to carry loads up to $6 \mathrm{~kg}$ and is controlled remotely up to a distance of $1000 \mathrm{~m}$, making it ideal for our application. The original design of the boat was altered and customized to accommodate our needs with specific parts of the watercraft machined at our laboratory. The decision to use a remotely controlled boat, as opposed to a manned watercraft, aimed to eliminate life-threatening risks associated with a possible rapid drainage of the lake (e.g., Das et al., 2008).

The boat was deployed on 2, 3 and 5 July 2010, on the west margin of the GrIS (Lake Olivia, $69^{\circ} 36^{\prime} 35^{\prime \prime} \mathrm{N}$, $49^{\circ} 29^{\prime} 40^{\prime \prime} \mathrm{W}$ ), with deployment time usually occurring when the sun was at zenith and measurements lasting for a few hours. As the boat average speed was $1 \mathrm{~ms}^{-1}$ and the GPS data were recorded every second, we estimate a spatial resolution of $1 \mathrm{~m}$ for the in-situ data. The spectral $(450-1050 \mathrm{~nm}$, with a $0.3 \mathrm{~nm}$ resolution) and depth data collected between two subsequent GPS acquisitions were averaged and assigned to the first of the two GPS locations. The total number of samples used in our analysis is $\sim 6000$. Though the boat here used is much smaller than manned boats and casts a relatively small shadow, we acknowledge that this might still be a source of uncertainty. During the maneuvering of the boat, we paid attention in avoiding that the boat would not cast a shadow across the instrumental field-of-view while driving it. Another mitigating factor includes the use of the arm on the side of the boat in order to position the spectral sensor at a certain distance from the hull.

The irradiance and radiance sensors were cross-calibrated in the laboratory following Mueller (2003). The diffuse irradiance leaving the outlet of an integrating sphere, illuminated by a calibrated xenon lamp, was measured by the irradiance sensor directed at the outlet. Radiance measurements were then taken of a Spectralon@ $\bigodot$ target (99\% reflectance) put in place of the irradiance sensor. These measurements were used to derive reflectance from irradiance and radiance intensity measurements and cross-calibrate the two sensors. Though spectral data were collected up to $1050 \mathrm{~nm}$, we focus our analysis on the $450-650 \mathrm{~nm}$ range. The reason for 


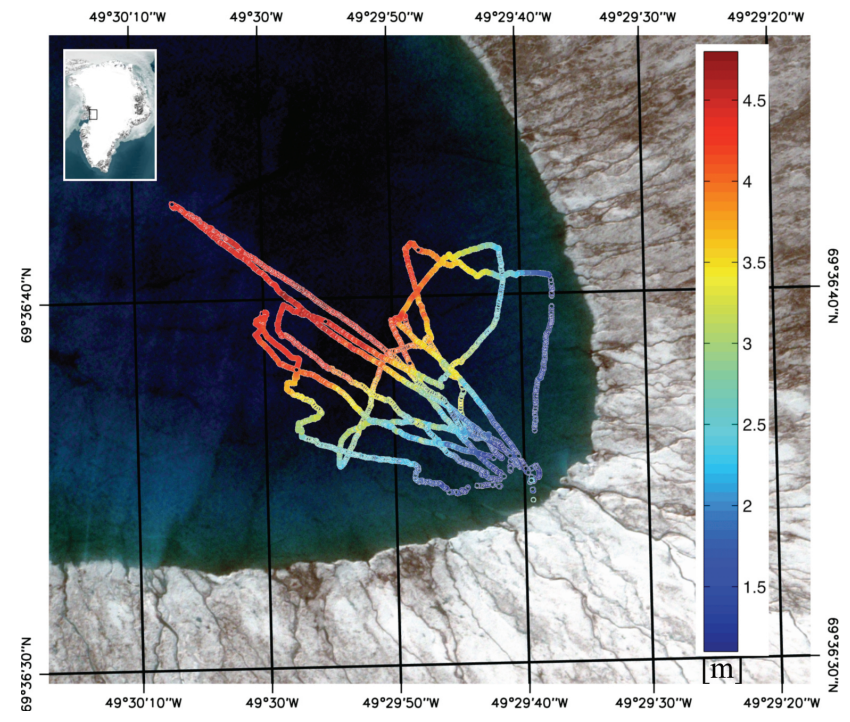

Fig. 2. Boat paths and measured depth values imposed over a highresolution $(0.5 \mathrm{~m})$ Wordlview-2 image.

this choice is related to the strong absoprtion (e.g., low reflectance) at wavelenghts above $\sim 650 \mathrm{~nm}$. As shown in the literature (e.g., Sneed and Hamilton, 2007), this can be used to increase the sensitivity to lake detection with respect to the use of wavelengths around or below $650 \mathrm{~nm}$. However, the strong absoprtion in the near-infrared region compromises the use of such band for depth retrieval. Because in this study we are mostly interested in assessing lake depth retrieval, rather than lake detection, we focus on wavelenghts below $650 \mathrm{~nm}$. We also note that, as a consequence of the strong absorption by water in the near infrared region, in-situ spectral measurements in that band for lake depth above a few tens of centimeters were characterized by an extremely low signal/noise ratio (e.g., comparable to the dark current measurement) and were, therefore, excluded from our analysis. Measurements for lake depth values less than $1 \mathrm{~m}$ are also excluded from our analysis because of the relatively small sensitivity of the reflectance data in the Landsat and MODIS blue and green bands to shallow waters.

\section{Analysis of in-situ data}

The boat paths and the corresponding measured depth are superimposed in Fig. 2 on a high-resolution $(0.5 \mathrm{~m})$ image collected on 4 July 2010 by the WorldView-2 sensor (http://worldview2.digitalglobe.com/). Shallow waters are generally located along the edge of the lake, with depth increasing toward its center, up to $\sim 4.5 \mathrm{~m}$. In Fig. 3 we plot the in-situ water-leaving reflectance spectrally averaged over the Landsat band 1 (B1 $1_{\text {LANDSAT }}, 450-515 \mathrm{~nm}$ ), band 2 (B2 LANDSAT, 525-605 $\mathrm{nm}$ ) and band 3 (B3 LANDSAT, $_{\text {, }}$, $630-690 \mathrm{~nm})$ vs. the in-situ measured lake depth. In-situ

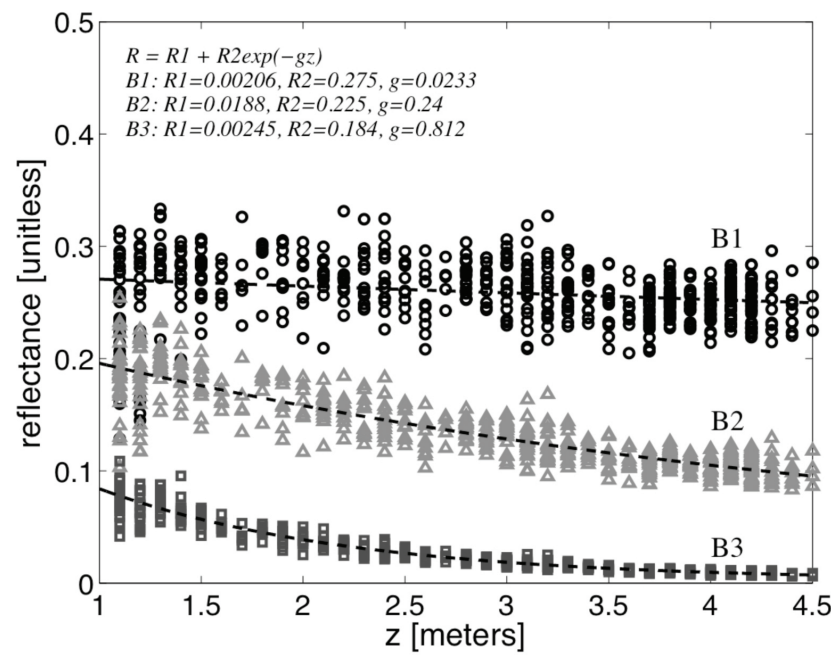

Fig. 3. In-situ measured water-leaving reflectance values vs. lake depth for the Landsat bands 1, 2 and 3 and exponential fitting.

measured water-leaving reflectance is fitted with Eq. (1), using $A d, g$ and $R_{\infty}$ as free fitting parameters. The values obtained for $g$ are: $g_{\text {B1_LANDSAT_fit }}=0.023 \mathrm{~m}^{-1}$, $g_{\text {B2_LANDSAT_fit }}=0.24 \mathrm{~m}^{-1}$ and $g_{\text {B3_LANDSAT_fit }}=0.81$ $\mathrm{m}^{-1}$. The corresponding $g$ values obtained assuming $g=2 K d$ (with $K d$ obtained from Pope and Fry, 1997) are $\quad g_{\text {B1_LANDSAT_2Kd }}=0.045 \mathrm{~m}^{-1}, \quad g_{\text {B2_LANDSAT_2 } K d}=$ $0.21 \mathrm{~m}^{-1}$ and $g_{\text {B3_LANDSAT_ } 2 K d}=0.65 \mathrm{~m}^{-1}$. The fitted values of $g$ are consistent with those computed assuming $g=2 K d$, though differences exist.

To address these differences, we analyzed the spectral dependency of the bottom albedo $A d$ and of the coefficient $\alpha$. Figure $4 \mathrm{a}$ and $\mathrm{b}$ show, respectively, the values of $\alpha$ (Fig. 4a) and $A d$ (Fig. 4b) in the 450-650 nm region obtained by minimizing the difference between measured water-leaving reflectance values and those simulated using Eq. (1), with $\alpha$, Ad and $R_{\infty}$ as free fitting parameters and $z$ measured insitu. For convenience, the values for $R_{\infty}$ are incorporated in Fig. $4 c$, though this parameter is excluded from our analysis. The iterative fitting procedure terminates when the difference between measured and simulated water leaving reflectance, $\Delta R$, is smaller than a threshold value $\Delta R_{T}$. The sensitivity of the fitting procedure to the choice of $\Delta R_{T}$ is shown Fig. 4, where bars represent the range of the fitted coefficients when $\Delta \mathrm{R}_{T}$ is set to $0.01,0.025,0.05$ and 0.1 . The spectrally averaged values for $\alpha$ for the Landsat bands 1 and 2 and the spectrally similar MODIS bands 3 and 4 are, respectively: $\alpha_{\text {B1 LLANDSAT }}=1.91, \alpha_{\text {B2 LANDSAT }}=$ $2.33, \alpha_{\mathrm{B} 3 \_ \text {MODIS }}=1.73$ and $\alpha_{\mathrm{B} 4 \text { _MODIS }}=2.4$. For the lake under study, the optimal (fitted) values for $\alpha$ differ by $~$ $+15 \%(-15 \%)$ from the constant value of $\alpha=2$. An error of $15 \%$ on $\alpha$ translates into a lake depth retrieval error of $\sim 17 \%$ when using the Landsat band 2 . Figure 4 also suggests that $\alpha$ increases with wavelength, which cannot be 


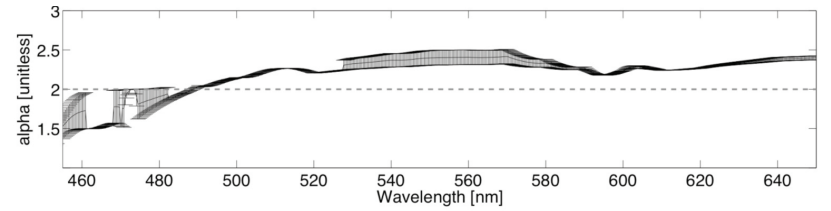

(a)

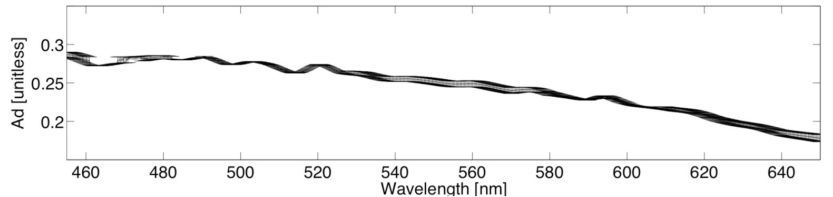

(b)

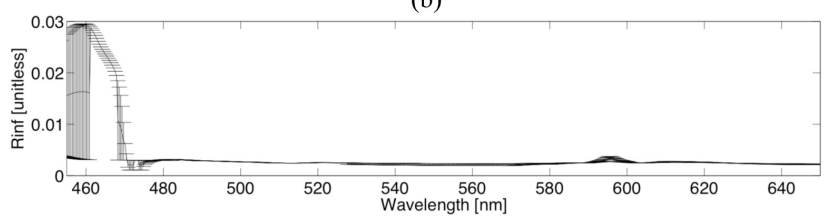

(c)

Fig. 4. Spectral dependency of $\alpha$ (top) and $A d$ (bottom) values derived from the minimization of the difference $\Delta R$ between measured and theoretical water-leaving reflectance values. Bars represent the range of values when different $\Delta R$ values are used (see text for details).

easily explained, aside from a possible chlorophyll concentration in the water, currently considered to be unlikely. A possible explanation is a higher variability of lake-bottom albedo in the blue region, producing a higher degree of uncertainty in our approximated $\alpha$ in that range.

The fitted values of $A d$ are greater at shorter wavelength and decrease with increasing wavelength, displaying a spectral behavior similar to that of glacier ice albedo (e.g., Grenfell and Perovich, 2004). To evaluate the assumption of estimating the value of $A d$ from the reflectance of shallow waters, we use data collected by Landsat over Lake Olivia on 9 July 2010 (http://glovis.usgs.gov), converted into planetary reflectance following Chander et al. (2009). Though Landsat and in-situ data were not collected on the same day, we assume that the lake depth did not change considerably between 6 and 9 July. This is supported by the small depth change $(<0.2 \mathrm{~m})$ recorded by a pressure transducer positioned into the lake during the period 1-6 July and by the simple visual analysis of daily WorldView-2 radiances collected between 4 and 9 July. Refletcance values at the top of the atmosphere (TOA) were corrected for atmospheric effects using the Fast Line-of-sight Atmospheric Analysis of Spectral Hypercubes (FLAASH) atmospheric correction ( Alder-Golden et al., 1999) implemented in the software ENVI®. In absence of atmospheric data, to simulate mid-summer conditions over the section of Greenland under study, the FLAASH model was initialized using a mid-latitude winter atmospheric model and maritime aerosol model. Aerosol optical depth was calculated using a 2-band VIS and SWIR ratio method using band 3 and 7 respectively

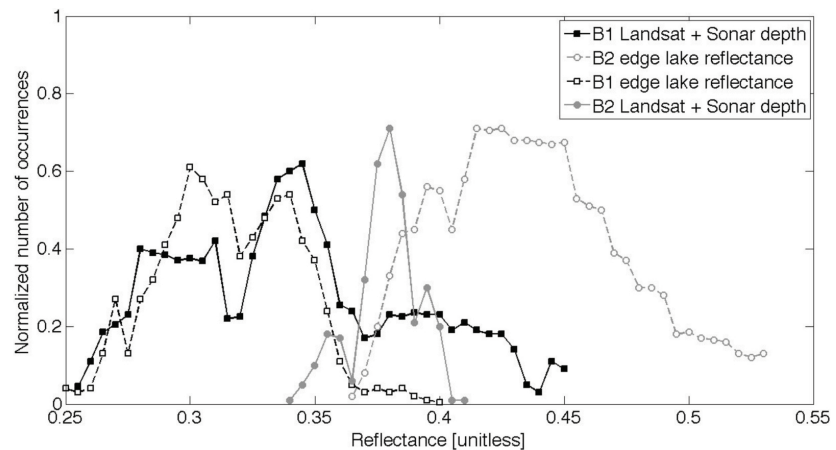

Fig. 5. Distribution of $A d$ values for the Landsat bands 1 and 2 estimated from Eq. (2) using lake depth measured by the boat (cont. lines) and of reflectance values from the edge lake (dashed lines).

( Kaufman et al., 1997). The average difference between atmospherically corrected and TOA reflectance values over the lake was $-3.9 \%( \pm 0.98 \%)$ in the case of band 1 and $-2.4 \%$ $( \pm 2.1 \%)$ for band 2 . The choice of the atmospheric model applied to the TOA reflectance values can be a source of uncertainty on the lake depth estimates. This uncertainty cannot be estimated in absence of information on the vertical profile of the atmospheric parameters used in the model. However, we decided to use the atmospherically corrected reflectance values for our analysis for consistency with the MODIS data used in this study.

Figure 5 illustrates the distribution of $A d$ for the Landsat band 1 (black lines) and band 2 (gray lines) obtained resolving Eq. (2) for $A d$, with $z$ obtained from insitu measurements and $R_{\infty}$ from the Landsat image where deep water $(z>40 \mathrm{~m})$ is present (e.g., Sneed and Hamilton, 2007). The distributions of the reflectance values at the two bands estimated from pixels along the lake edge are also plotted. The mean $A d$ values obtained from solving Eq. (2) are $A d_{\text {LANDSAT_B1 }}=0.37 \pm 0.012$ and $A d_{\text {LANDSAT_B2 }}=0.3 \pm 0.024$; the mean reflectance values for pixels along the lake edge are $R_{\text {Edge_B } 1}=0.42 \pm 0.058$ for band 1 and $R_{\text {Edge_B2 }}=0.34 \pm 0.062$ for band 2 . The percentage error between the mean $A d$ value and the mean of the reflectance values along the lake edge is $\sim 10 \%$ in both cases of the blue and green Landsat bands. From Eq. (2), this translates into an average error on lake depth retrieval between $\sim-10 \%$ and $\sim-15 \%$ when using, respectively, the Landsat bands 1 or 2 . The error on depth is maximum for shallow waters with an underestimation down to $\sim-25 \%$ (blue) and $\sim-40 \%$ (green) and reduces to $\sim-5 \%$ for both channels for lake depth values up to $10 \mathrm{~m}$.

\section{Assessment of lake depth from satellite data}

Here we compare the lake depth values estimated with Landsat and MODIS with those measured in-situ. Table 1 reports the mean, standard deviation and maximum values 
Table 2. Statistics on lake depth retrieval using different sensors, bands and hypothesis on the bottom albedo values $A d$.

\begin{tabular}{|c|c|c|c|c|c|c|c|}
\hline & Mean $[\mathrm{m}]$ & Std. dev. $[\mathrm{m}]$ & Max. $[\mathrm{m}]$ & RMSE $[\mathrm{m}]$ & $\operatorname{MAE}[\mathrm{m}]$ & Correlation & $\%$ absolute error \\
\hline & \multicolumn{7}{|c|}{ SONAR } \\
\hline & 2.83 & 0.97 & 4.55 & $\mathrm{n} / \mathrm{a}$ & $\mathrm{n} / \mathrm{a}$ & $\mathrm{n} / \mathrm{a}$ & $\mathrm{n} / \mathrm{a}$ \\
\hline \multicolumn{8}{|c|}{ Landsat } \\
\hline \multicolumn{8}{|c|}{ BAND 1 (450-515 nm) } \\
\hline$A d=\mu_{\text {AdLANDSAT_B1 }}$ & 2.98 & 1.62 & 5.68 & 0.99 & 0.65 & 0.78 & 3.71 \\
\hline$A d=\mu_{\text {Edge } \_B 1}$ & 5.93 & 1.63 & 8.47 & 3.15 & 2.96 & 0.77 & 121.8 \\
\hline \multicolumn{8}{|c|}{ BAND 2 (525-605 nm) } \\
\hline$A d=\mu_{\text {AdLANDSAT_B2 }}$ & 3.01 & 0.98 & 4.57 & 0.63 & 0.51 & 0.85 & 4.21 \\
\hline$A d=\mu_{\text {Edge } \_B 2}$ & 3.47 & 0.95 & 4.92 & 0.82 & 0.63 & 0.87 & 17.91 \\
\hline \multicolumn{8}{|c|}{ MODIS } \\
\hline \multicolumn{8}{|c|}{ BAND 3 (459-479 nm) } \\
\hline TERRA [2 through 5 July] & 6.5 & 1.93 & 8.65 & $\mathrm{n} / \mathrm{a}$ & $\mathrm{n} / \mathrm{a}$ & $\mathrm{n} / \mathrm{a}$ & $\mathrm{n} / \mathrm{a}$ \\
\hline AQUA [2 through 5 July] & 2.3 & 1.47 & 4.14 & $\mathrm{n} / \mathrm{a}$ & $\mathrm{n} / \mathrm{a}$ & $\mathrm{n} / \mathrm{a}$ & $\mathrm{n} / \mathrm{a}$ \\
\hline \multicolumn{8}{|c|}{ BAND 4 (545-565 nm) } \\
\hline TERRA [2 through 5 July] & 2.1 & 0.92 & 2.9 & $\mathrm{n} / \mathrm{a}$ & $\mathrm{n} / \mathrm{a}$ & $\mathrm{n} / \mathrm{a}$ & $\mathrm{n} / \mathrm{a}$ \\
\hline AQUA [2 through 5 July] & 0.9 & 0.9 & 1.9 & $\mathrm{n} / \mathrm{a}$ & $\mathrm{n} / \mathrm{a}$ & $\mathrm{n} / \mathrm{a}$ & $\mathrm{n} / \mathrm{a}$ \\
\hline
\end{tabular}

of lake depth obtained from satellite data, together with the root mean square error, the mean absolute error, correlation and percentage error between spaceborne-estimated lake depth using either Landsat and $500 \mathrm{~m}$ MODIS reflectance product (http://modis.gsfc.nasa.gov/data/dataprod/ dataproducts.php?MOD_NUMBER=09) and the values measured by the sonar. Results obtained from MODIS are averaged over the period 2-5 July 2010, when in situ data were collected. We decided to use the abovementioned MODIS product (rather than correcting level 1 MODIS data for atmopshere and extract reflectance values) because of the potential large use of such product in estimating spatiotemporal variability of supraglacial lakes at a relatively low computational cost. However, we point out that the MODIS reflectance product (MOD09) makes use of multiple daily observations. Within each tile, areas with clouds or low elevation sun angles are not used and other criteria are applied to select those observations used to generate the product (http://modis-sr.ltdri.org/products/MOD09_ UserGuide_v1_3.pdf). Consequently data acquired at different times can be potentially used for generating the final product. We also point out that the MODIS nominal spatial resolution of $250 \mathrm{~m}$ is only valid for those cases when the observation angle is close to nadir. When the target is on the side of the swath, the instantaneous field of view (IFOV) becomes larger and, hence, a larger surface is responsible for the reflectance value. If this surface contains the lake edge, the overall reflectance might be higher than the one obtained when the observation angle was close to nadir, because of the presence of ice or snow. Lastly, another factor affecting the remote sensing algorithm is the presence of ice on the lake surface, which has been observed from the analysis of high resolution visible images and during our fieldwork.

Results obtained in the case of MODIS when using either $\alpha=2$ or the values of $\alpha$ obtained from the fitting procedure above described (Fig. $4 \mathrm{~b}$ ) are reported. The values of the bottom albedo $A d$ are obtained from the mean of the reflectance of shallow waters on the edge of the lake (e.g., Sneed and Hamilton, 2007). As a reference, the mean, standard deviation and maximum depth of the lake depth values measured by the sonar are also shown in the first row of the table. Results indicate that the use of the Landsat band 1 tends to overestimate lake depth, with an RMSE ranging between 2.7 and $3 \mathrm{~m}$, a maximum lake depth on the order of $8 \mathrm{~m}$ (against the value of $4.55 \mathrm{~m}$ measured in situ) and a mean value of $\sim 6 \mathrm{~m}$. Lake depth is also overestimated when using the MODIS band 3, that is spectrally similar to the Landsat band 1. Maximum depth values from MODIS are close to those estimated by Landsat band 1 but the mean values from MODIS are higher than those obtained with Landsat. Results improve when using either the Landsat band 2 or MODIS band 4, with mean depth values ranging between $0.71 \mathrm{~m}$ (AQUA) and $3.64 \mathrm{~m}$ (Landsat). Best results are obtained with Landsat when using $\alpha=2.33$ (from fitting). In this case, mean, standard deviation and maximum depth provide the closest estimates to the measured ones, with a RMSE 
of $0.59 \mathrm{~m}$. MODIS band 4 tends to underestimate lake depth with respect to in-situ data. In the case of MODIS, the use of the $\alpha$ fiitted value deteriorates the performance of the remote sensing algorithm, further reducing the values of the estimated lake depths.

In Table 2 we report the results of our analysis aimed at quantifying the error on lake depth retrieval from the assumptions of a uniform $A d$ value for the whole lake and using the reflectance values of the pixels at the edge of the lake for $\mathrm{Ad}$. Lake depth values are estimated using Eq. (2), with $A d$ values given by the mean of the distributions of the bottom albedo values obtained form the concurrent analysis of surface and satellite data or by the mean of the reflectance values along the lake edge. The table includes the mean, standard deviation, maximum value of lake depth obtained from the satellite data together with the root mean square error, the mean absolute error, correlation and percentage error between the lake depth values estimated with the different configurations and the values measured by the sonar. Results from both Landsat (bands 1 and 2) and MODIS (bands 3 and 4) are reported. In general, best results are obtained when using the Landsat band 2 when $A d$ is given by the mean of the $A d$ distribution computed from the conjunct analysis of satellite and surface data. Depth estimates using Landsat band 1 show a larger standard deviation and higher maximum depth values (above the maximum measured depth), likely as a consequence of the smaller diffuse attenuation coefficient in the blue band (Smith and Baker, 1980; Pope and Fry, 1997). Maximum lake depth values estimated when using Landsat band 2 are closer to the value measured in situ. The MODIS sensor on TERRA provides smaller lake depth values than those obtained with the one mounted on AQUA. Given the short timeseries it is not possible to assess whether this is a consistent bias. The values estimated by MODIS on TERRA are the closest to those estimated by Landsat and measured in situ. Lake depth values estimated from MODIS when using band 4 are generally smaller than those measured in situ.

\section{Conclusions and future work}

We collected in-situ concurrent multi-spectral and depth observations over a supraglacial lake in West Greenland in order to assess spaceborne bathymetry. Such measurements allowed us to study the spectral dependency of the bottom albedo $A d$ and coefficient $\alpha$ with the latter linearly relating the attenuation coefficient $g$ and the diffuse attenuation factor $K d$. Results show that, as expected, the spectral behavior of $A d$ is similar to that of glacier ice albedo. The increase of $\alpha$ with wavelength from in-situ data cannot be easily explained without assuming chlorophyll, or other absorbing material, in the water, which is present in very minimal concentrations according to our preliminary analysis of water samples. One explanation for the spectral behavior of $\alpha$ is that the bottom albedo has a higher variability in the blue region, attributing some of the loss due to a darker blue ice to loss along the water column.

We assessed a widely used literature technique in which $A d$ is assumed to be uniform and equal to the reflectance of shallow waters along the lake edge. The analysis of in-situ measurements show a Gaussian-like behavior of $A d$, with this variability appearing to be intrinsic to the albedo of the bottom, consisting of large patches of cryoconite. The difference between the mean $A d$ value obtained from in-situ measurements and the mean of the reflectance values along the lake edge obtained from Landsat is on the order of $\sim 10 \%$. This translates into an average error on lake depth retrieval of $-11.8 \%(-15.9 \%)$ when using the Landsat band 1 (band 2 ). The error is maximum for shallow waters with an underestimation down to $-23.7 \%(-42.7 \%)$ and reduces to $-4.6 \%$ $(-4.7 \%)$ for lake depth values up to $10 \mathrm{~m}$.

In the case of $\alpha$, the values obtained from in-situ measurements differ by $\sim 15 \%$ from those computed using literature approaches. Best spaceborne-based estimates were obtained when using either the Landsat band 2 or the spectrally similar MODIS band 4. In the case of Landsat, best results are obtained when using the $\alpha$ value derived from in-situ measurements $(\alpha=2.33$. However, this is not true in the case of MODIS, where best results are obtained using the values suggested in the literature $(\alpha=2)$. In the case of MODIS, however, mixed-pixel effects and relatively coarse resolution can be responsible for large uncertainty. For example, the presence of ice within a pixel will increase the reflectance with respect to a pixel containing only liquid water, leading to an underestimation of the lake depth. This is especially true for relatively small lakes and for those pixels containing the lake edges. In the future, we plan to collect a more comprehensive in-situ data set on the inherent optical properties of melt pond water and to extend our analysis to multiple lakes. We also plan to use a more sophisticated model of the water column (Lee, 1999), in which depth estimations can be made with a fully physical model of water constituents.

Acknowledgements. This work was supported by the NSF grant ANS 0909388 and by the NASA Cryosphere Program. Fieldwork activities were partially supported by the World Wildlife Foundation (WWF). Thanks to Mark Jenkins (National Geographic), James Balog and Adam Lewinter (Extreme Ice Survey, EIS) for sharing their fieldwork knowledge and their logistical support. We are deeply grateful to Jim "Soup" Rios for leading the safety and rescue section of our camp and for logistical support at Lake Olivia. Thanks to Gordon Hamilton and an anonymous reviewer for their suggestions aimed at improving the quality of this manuscript. We also thank Tristan Schwartzman for processing the boat data at CCNY.

Edited by: S. Dery 


\section{References}

Adler-Golden, S. M., Matthew, M. W., Bernstein, L. S., Levine, R. Y., Berk, A., Richtsmeier, S. C., Acharya, P. K., Anderson, G. P., Felde, G., Gardner, J., Hoke, M., Jeong, L. S., Pukall, B., Ratkowski, A., and Burke H.-H.: Atmospheric Correction for Short-wave Spectral Imagery Based on MODTRAN4. SPIE Proc. Imaging Spectrom., 3753, 61-69, 1999.

Box, J. E. and Ski, K.: Remote sounding of Greenland supra-glacial melt lakes: implications to sub-glacial hydraulics, J. Glaciol., 181, 257-265, 2007.

Chander, G., Markham, B. L., and Helder, D. L.: Summary of current radiometric calibration coefficients for Landsat MSS, TM, ETM+, and EO-1 ALI sensors, Remote Sens. Environ., 113, 893-903, 2009.

Das, S. B., I. Joughin, M. D. Behn, I. M. Howat, M. A. King, D. Lizarralde and M. P. Bhatia: Fracture propagation to the base of the Greenland ice sheet during supraglacial lake drainage, Science, 320, 778-781, 2008.

Georgiu, S., Shepherd, A., McMillan, M., and Nienow, P.: Seasonal evolution of supraglacial lake volume from ASTER imagery, Ann. Glaciol., 50(52), 95-100, 2009.

Grenfell, T. C. and Perovich, D. K.: Seasonal and spatial evolution of albedo in a snow-ice-land-ocean environment, J. Geophys. Res., 109, C01001, doi:10.1029/2003JC001866, 2004.

Joughin, I., Tulaczyk, S., Fahnestock, M., and Kwok, R.: A minisurge on the Ryder Glacier, Greenland, observed by satellite radar interferometry, Science, 274, 228-230, 1996.

Kaufmann, Y. J., Wald, A. E., Remer, L. A., Gao, B.-C., Li, R.-R., and Flynn, L.: The MODIS 2.1-mm Channel-Correlation with Visible Reflectance for Use in Remote Sensing of Aerosol. IEEE T. Geosci. Remote Sens., 35, 1286-1298, 1997.

Lee, Z., Carder, K. L., Mobley, C. D., Steward, R. G., and Patch, J. S.: Hyperspectral remote sensing for shallow waters. 2. Deriving bottom depths and water properties by optimization, Appl. Optics, 38(18), 3831-3843, 1999.

Lüthje, M., Pedersen, L. T., Reeh, N., and Greuell, W.: Modelling the evolution of supra-glacial lakes on the West Greenland icesheet margin, J. Glaciol., 52, 608-618, 2006.

Maritorena, S., Morel, A., and Gentili, B.: Diffuse reflectance of oceanic shallow waters: Influence of water depth and bottom albedo, Limnol. Oceanogr., 39(7), 1689-1703, 1994
McMillan, M., Nienow, P., Shepherd, A., Benham, T., and Sole, A.: Seasonal evolution of supra-glacial lakes on the Greenland ice sheet, Earth Planet. Sci. Lett., 262, 484-492, 2007.

Mobley, C. D.: Estimation of the remote-sensing reflectance from above-surface measurements, Appl. Optics, 38(36), 7442-7455, 1997.

Mueller, J.: In-Water Radiometric Profile Measurements and Data Analysis Protocols, NASA/TM-2003-21621/Rev-Vol III, 7, 2003.

Mueller, J., McClain, G., Bidigare, R., Trees, C., Balch, W., Dore, J., Drapeau, D., Karl, D., and Van, L.: Ocean optics protocols for satellite ocean color sensor validation, revision 5, volume V: Biogeochemical and bio-optical measurements and data analysis protocols, NASA Tech. Memo. 2003-211621, Rev, 5, 2003.

Philpot, W. D.: Bathymetric mapping with passive multispectral imagery, Appl. Optics, 28(8), 1569-1578, 1989.

Pimentel, S. and Flowers, G. E.: A numerical study of hydrologically driven glacier dynamics and subglacial flooding, Proc. R. Soc. A, 467, 537-558, doi:10.1098/rspa.2010.0211, 2011.

Pope, R. M. and Fry, E. S.: Absorption spectrum (380-700 nm) of pure water. II. Integrating cavity measurements, Appl. Opt., 36, 8710-8723, 1997.

Smith, R. C. and Baker, K. S.: Optical properties of the clearest natural waters (200-800 nm), Appl. Optics, 20(2), 177-184, doi:10.1364/AO.20.000177, 1981.

Sneed, W. A. and Hamilton, G. S.: Evolution of melt pond volume on the surface of the Greenland Ice Sheet, Geophys. Res. Lett., 34, L03501, doi:10.1029/2006GL028697, 2007.

Sundal, A. V., Shepherd, A., Nienow, P., Hanna, E., Palmer, S., and Huybrechts, P.: Evolution of supra-glacial lakes across the Greenland Ice Sheet, Remote Sens. Environ., 113, 2164-2171, 2009.

Tedesco, M., Fettweis, X., van den Broeke, M. R., van de Wal, R. S. W., Smeets, C. J. P. P., van de Berg, W. J., Serreze, M. C., and Box, J. E.: The role of albedo and accumulation in the 2010 melting record in Greenland, Environ. Res. Lett., 6, 014005, 2011. 